\title{
TRITIUM BEHAVIOR IN ITER BERYLLIUM
}

\author{
Glen R. Longhurst
}

October 1990

\author{
Idaho National Engineering Laboratory \\ EG\&G Idaho, Inc. \\ P. 0. Box 1625 \\ Idaho Falls, ID 83415
}

Work supported by the U.S. Department of Energy, Director of Energy Research, Office of Fusion Energy under DOE Contract No. DE-ACO776 ID01570. 


\section{CONTENTS}

ABSTRACT

INTRODUCTION

TRITIUM SOURCES

HELIUM BEHAVIOR

4

OTHER PROCESSES . . . . . . . . . . . . . . . . . . . 7

Chemical Reactions ..................... . 7

Self Diffusion ..................... . . . . 7

TRITIUM MOVEMENT AND RELEASE . . . . . . . . . . . . . . . . . 8

Conceptual Model . . . . . . . . . . . . . . . . . 8

Release Experiments... . . . . . . . . . . . . . . . 11

Idealizations . . . . . ............... 11

Recombination .................. 12

Other ..................... 17

Breakaway ................... 18

Tritium Storage ................. 19

EVOLUTION MODEL . . . . . . . . . . . . . . . . . . . 22

CONCLUSIONS . . . . . . . . . . . . . . . . . . . . 28

REFERENCES ......................... . . . 29 


\section{ABSTRACT}

The beryllium neutron multiplier in the ITER breeding blanket will generate tritium through transmutations. That tritium constitutes a safety hazard. Experiments evaluating tritium storage and release mechanisms have shown that most of the tritium comes out in a burst during thermal ramping. A small fraction of retained tritium is released by thermally activated processes. Analysis of recent experimental data shows that most of the tritium resides in helium bubbles. That tritium is released when the bubbles undergo swelling sufficient to develop porosity that connects with the surface. That appears to occur when swelling reaches about $10-15 \%$. Other tritium appears to be stored chemically at oxide inclusions, probably as $\mathrm{Be}(\mathrm{OT})_{2}$. That component is released by thermal activation. There is considerable variation in published values for tritium diffusion through the beryllium and solubility in it. Data from experiments using highly irradiated beryllium from the Idaho National Engineering Laboratory showed diffusivity generally in line with the most commonly accepted values for fully dense material. Lower density material, planned for use in the ITER blanket may have very short diffusion times because of the open structure. The beryllium multiplier of the ITER breeding blanket was analyzed for tritium release characteristics using temperature and helium production figures at the midplane generated in support of the ITER Summer Workshop, 1990 in Garching. Ordinary operation, either in Physics or Technology phases, should not result in the release of tritium trapped in the helium bubbles. Temperature excursions above $600^{\circ} \mathrm{C}$ result in large-scale release of that tritium. 


\title{
TRITIUM BEHAVIOR IN ITER BERYLLIUM
}

\author{
INTRODUCTION
}

Beryllium will be used in the ITER breeding blanket as a neutron multiplier. Several configuration options are being considered including Be pebbles and blocks. ${ }^{1}$ Plasma-sprayed Be is also being explored as a plasmafacing material for the divertor and first-wall structures. We know from experience the approximate amount of tritium that will be produced in the $\mathrm{Be}$ but the production rate estimate needs refinement. Less certain are the emission characteristics of this tritium under normal operating conditions and particularly in the event of an aciident involving a therlial iransient. The objective of this work is to explore the information available that would lead to a mechanistic model for such release and attempt to forecast the magnitude and approximate rate of release for a postulated accident in ITER. This analysis considers only solid Be in the pebble or block form. Plasma-sprayed $B e$ is expected to be quite different in character from this reference material.

\section{TRITIUM SOURCES}

The main source of tritium in Be is the reaction chain

$$
\begin{aligned}
& { }^{9} \mathrm{Be}+n-{ }^{6} \mathrm{He}+\alpha \\
& { }^{6} \mathrm{He}-{ }^{6} \mathrm{Li}+\beta^{-} \\
& { }^{6} \mathrm{Li}+\mathrm{n}-{ }^{3} \mathrm{H}+\alpha
\end{aligned}
$$

The first of these reactions has a threshold at $600 \mathrm{keV}$ with a strong resonance ( 0.105 barn) at $3 \mathrm{MeV}$. The reaction

$$
{ }^{9} \mathrm{Be}+\mathrm{n}-{ }^{6} \mathrm{Li}+{ }^{3} \mathrm{H}
$$

is also possible in a fusion reactor, but it is not seen much in fission reactor data because of its $10.4 \mathrm{MeV}$ threshold. 
Also, there may be some Li impurity $(-200$ appm for the MgF process, $<20$ appm from the bertrandite process). ${ }^{2}$ The ${ }^{6} \mathrm{Li}$ component in the impurity (about $7 \%$ ) reacts with thermal neutrons in the last of reactions (1) while the ${ }^{7} \mathrm{~L} i$ has the threshold reaction with fast neutrons

$$
{ }^{7} L i+n-{ }^{3} H+\alpha+n .
$$

A substantial amount of $\mathrm{He}$ is produced with the tritium. The ${ }^{9} \mathrm{Be}(n, 2 n)$ ${ }^{8} \mathrm{Be}$ reaction for which the $\mathrm{Be}$ is used in ITER terminates in the production of two $\alpha$ particles. The rate of He production in Be is proportional to neutron fluence but varies with neutron energy spectrum. Table 1 lists some measured values for comparison. Generally, the fast-flux fission reactors exhibit less He production because it is produced by threshold reactions, and the actual number of neutrons with energies sufficient to produce the $H e$ is less in the fast fission reactors. In fusion reactors where the spectrum has a strong peak in excess of $14 \mathrm{MeV}$, the production rate should be higher than in fission reactors. Two separate calculations using a typical fusion spectrum give about $6600 \mathrm{appm} \mathrm{He} / 10^{22} \mathrm{n} / \mathrm{cm}^{2}$ ( $\mathrm{E}>1 \mathrm{MeV}$ ). ${ }^{3}$ Calculations made to estimate He production in the ITER blanket used $6000 \mathrm{appm} \mathrm{He} / 10^{22} \mathrm{n} / \mathrm{cm}^{2}(E>1 \mathrm{MeV}) .^{4}$

The ${ }^{4} \mathrm{He} /{ }^{3} \mathrm{H}$ ratio found in irradiated $\mathrm{Be}$ also varies depending on the neutron energy spectrum, the aging time for tritium decay, the mobility of the He produced, and the amount of $L i$ and other impurities; but it is typically between 7 and $17 .^{5}, 6$ Figure 1 shows a distribution of He/T ratios for several values of neutron fluence observed in data from Tromp, ${ }^{7}$ ETls \& Perryman, ${ }^{5}$ and Beeston et al. ${ }^{8}$ No clear trend is evident, but the average value is 17.2 .

There appears to be a strong correlation between the behavior of the He in the $\mathrm{Be}$ and the release characteristics of the tritium. He bubbles migrate and coalesce to form interconnected porosity, sometimes connected with the surface of the material. The observed release of large quantities of tritium from $B e$ at the same temperatures suggests there is a tendency for the tritium produced to follow the He into the bubbles and to be released with the He. 
Table 1. He production in Be by fission neutrons.

\begin{tabular}{|c|c|c|c|}
\hline Parameter & ATR $^{9}$ & $\mathrm{BR2} 10$ & EBR-II 11 \\
\hline $\begin{array}{l}\text { Irradiation } \\
\text { Temperature }\left({ }^{\circ} \mathrm{C}\right)\end{array}$ & 75 & 45 & $427-487$ \\
\hline Fluence $\left(10^{22} \mathrm{n} / \mathrm{cm}_{2}\right)$ & $1.4-3.4$ & $0.7-2.9$ & $0.8-1.3$ \\
\hline appm $\mathrm{He} / 10^{22} \mathrm{n} / \mathrm{cm}^{2}$ & 4400 & $2205-3730$ & 1540 \\
\hline $\begin{array}{l}\text { Maximum He } \\
\text { concentration, appm }\end{array}$ & 15000 & $6600 / 11200$ & 2000 \\
\hline
\end{tabular}

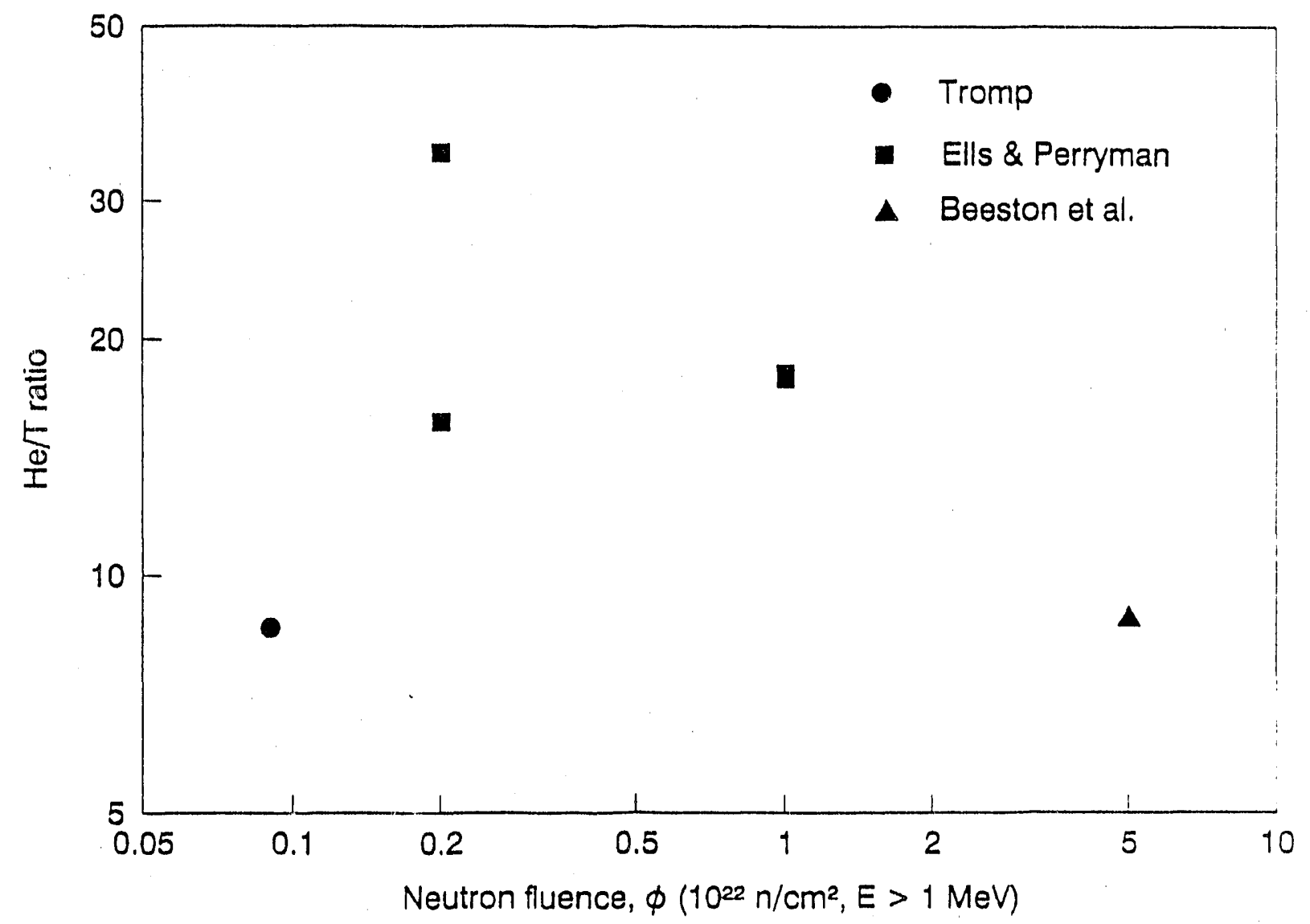

Figure 1. The He/T ratio produced in fission reactors shows considerable variation. 


\section{HELIUM BEHAVIOR}

Theories of swelling of irradiated materials and migration and coalescence of bubbles of inert gas in them have been under investigation and development for many years. ${ }^{12},{ }^{13}, 14$ To summarize, nuclear reactions result in a net increase in the number of atoms present. That causes some swelling just to accommodate these additional atoms. As inert gas atoms are formed in a metal matrix, they very quickly supersaturate the material (He is insoluble in metals) and precipitate as embryonic bubbles or clusters on any availabie nuclei such as dislocation loops, vacancies, inclusions, and grain boundaries. When sufficient energy is available for vacancy movement and/or self diffusion to take place, host atoms and entrained gas atoms move about the lattice. Coalescence of the gas atoms is energetically favored with the atoms in the resulting bubbles taking on the characteristic of a highly compressed gas only when there is sufficient volume available for the gas atoms to become separated from each other. The bubbles remain stable in size when

$$
\frac{.2 \gamma}{r_{0}}=p
$$

where $\gamma$ is the surface energy of the bubble (equivalent of surface tension), $r_{0}$ is the effective bubble radius at equilibrium, and $P$ is the gas pressure. Because of the accretion of gas atoms that wander to the bubble surface and become absorbed, there is a tendency for the bubbles to grow. Bubbles also move, either in random Brownian motion or under the influence of an applied force. When they collide, they coalesce. Because of the larger volume required after coalescence of two bubbles to satisfy Eq.(4), lattice atoms recede from the bubble site which causes additional swelling with a reduction in pressure inside the bubble.

Bubbles tend to collect at grain boundaries and inclusions. They also tend to become larger there than within the grains. As these bubbles become connected they may produce blistering or flaking or they may open up channels to the material surface, depending on the particular conditions. Development of open porosity aiso results in loss of gas from the metal lattice. A model that assumes bubbles of the same size with a uniform number density predicts 
bubble collision and growth rates based on random walk or driven bubble motion. ${ }^{12}$ This collision time obeys an Arrhenius law (is thermally activated) and can be correlated with experimentally observed swelling rates during annealing experiments. When a critical combination of bubble size and helium content has been achieved, the bubble coalescence solely due to growth rates from accretion overtakes that due to movement in the grain or along a grain boundary. This acceleration of bubble growth rates results in a departure from the monotonic Arrhenius nature of swelling and gas release and is called "breakaway". It has been observed in a number of experiments. ${ }^{12}$ Figure 2, after Rich, Redding, and Barnes, ${ }^{15}$ shows representative swelling data for Be irradiated in the Materials Test Reactor (MTR) to $7.6 \times 10^{21} \mathrm{n} / \mathrm{cm}^{2}$ (E > $\mathrm{MeV})$.

During constant heating rate experiments, there is a sudden increase in swelling when temperatures exceed a critical temperature, often in the vicinity of $600^{\circ} \mathrm{C}$. This corresponds to the "breakaway" described in theoretical treatments of swelling and is associated with a departure from thermally activated self-diffusion processes. It also corresponds with a general release of helium. Variations in swelling amount and time required for swelling to reach saturation are illustrated by the data of figure 2 . These variations are functions of initial metal density, composition, and irradiation history. In one set of post-irradiation experiments on $B e$ irradiated in the Advanced Test Reactor, bubble radii were observed by electron microscopy to grow linearly with annealing temperature."

The swelling process has been modelled by Barnes. ${ }^{12}$ His equation for swelling during irradiation at elevated temperature is

$$
\frac{\Delta V}{V}=\frac{k T a_{0}}{4}\left(\frac{3 D_{s} F \ln (t)}{\pi}\right)^{\frac{1}{4}}\left(\frac{\eta}{\gamma}\right)^{\frac{5}{4}} t^{\frac{3}{2}}
$$

where $k$ is Boltzmann's constant, $T$ is temperature, $a_{0}$ is the lattice constant, $\eta$ is the He production rate, $\gamma$ is the bubble surface energy (assumed to be $\left.1 \mathrm{~J} / \mathrm{m}^{2}\right), D_{\mathrm{s}}$ is the self diffusion constant, $F$ is the mobilization force (taken as $\left.10^{-9} \mathrm{~N}\right)$, and $t$ is irradiation time at elevated temperature. A similar 


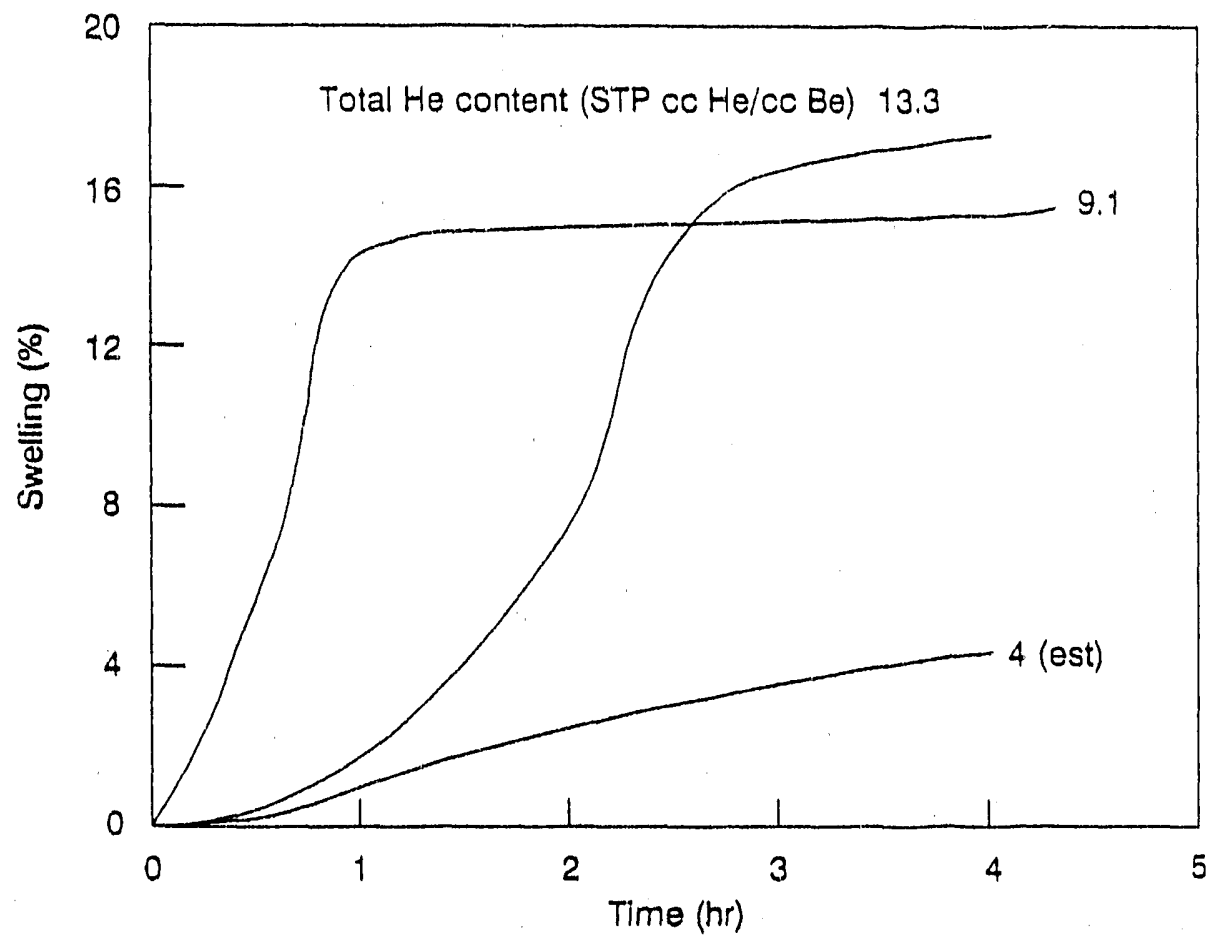

Figure 2. Helium release histories for three MTR samples held at $700^{\circ} \mathrm{C}$. Only the total gas release was published for the lowest curve.

expression,

$$
\frac{\Delta V}{V}=\frac{k T a_{0}}{4}\left(\frac{3 D_{s} F t}{\pi}\right)^{\frac{1}{4}}\left(\frac{\eta}{\gamma}\right)^{\frac{5}{4}}
$$

is given for swelling during post-irradiation anneals. The parameters in Eq. (6) have the same meanings except $\eta$ is the total He content and $t$ is the elapsed time of the anneal. Noting a nominal maximum possible swelling of $30 \%$, Barnes says "breakaway" swelling should be seen when swelling r. "ies about $10 \%$. Putting values for samples irradiated at the INEL and subsequently tested by Baldwin ${ }^{16}$ (discussed below) into Eq. (6) with a breakaway temperature of $884 \mathrm{~K}$ gave a critical value of swelling of $16 \%$, in good agreement with Barnes' theory. 


\section{OTHER PROCESSES}

\section{Chemical Reactions}

The temperature of $600^{\circ} \mathrm{C}$ is also approximately that at which a number of chemical reactions involving Be commence. For example, reactions of Be with $\mathrm{LiSO}_{3}$ begin at about $650^{\circ} \mathrm{C}$, and $\mathrm{Be}$ is stable in $\mathrm{LiSO}_{4}$ only to about $700^{\circ} \mathrm{C}$. The reaction of $\mathrm{Be}$ with stainless steel begins at $600^{\circ} \mathrm{C}$. It proceeds niore rapidly than the $\mathrm{LiSO}_{3}$ or $\mathrm{LiSO}_{4}$ reactions and results from the migration of $\mathrm{Be}$ atoms into the steel structure to form BeNi. ${ }^{17}$

\section{Self Diffusion}

An explanation for the relatively sudden onset of chemical activity at these temperatures is that $t_{1}$. Be metal atoms themselves become sufficiently mobile to penetrate the protective oxide coating. The self-diffusion coefficient, $D_{s}$, has been determined 18 to be given by

$$
D_{s}=0.52 \exp \left(-\frac{18,922}{T(K)}\right) \frac{\mathrm{cm}^{2}}{\mathrm{~s}} \text {. }
$$

Consider, now, the movement of atoms across a grain of the material. Swelling is thought to accompany collection of gas in the large bubbles that seem to prefer locations at grain boundaries. " The time constant for a selfdiffusion process that requires movement to the boundary of a grain $25 \mu \mathrm{m}$ in diameter is plotted as a function of temperature in Figure 3.

When the temperature approaches $600^{\circ} \mathrm{C}$, the transient times become typical of those seen in swelling and helium release experiments. These experiments are often conducted at temperature rates of a few ${ }^{\circ} \mathrm{C} / \mathrm{min}$ such that the tests last only a few hours. Notice that at $500^{\circ} \mathrm{C}$ the time required for trans-granular self diffusion is 35.7 hours while at $650^{\circ} \mathrm{C}$ the time has dropped to only 40.8 minutes. Hence, thermal activation of self diffusion should be considered as a possible mechanism responsible for the apparent unleashing of swelling and gas release.

\footnotetext{
- a Gas dispersed in very small bubbles will exist at much higher pressures (see Eq. (4)), and swelling will be minimal. One method for controlling swelling is the precipitation of small nucleation sites that tend to pin the small He bubbles.
} 


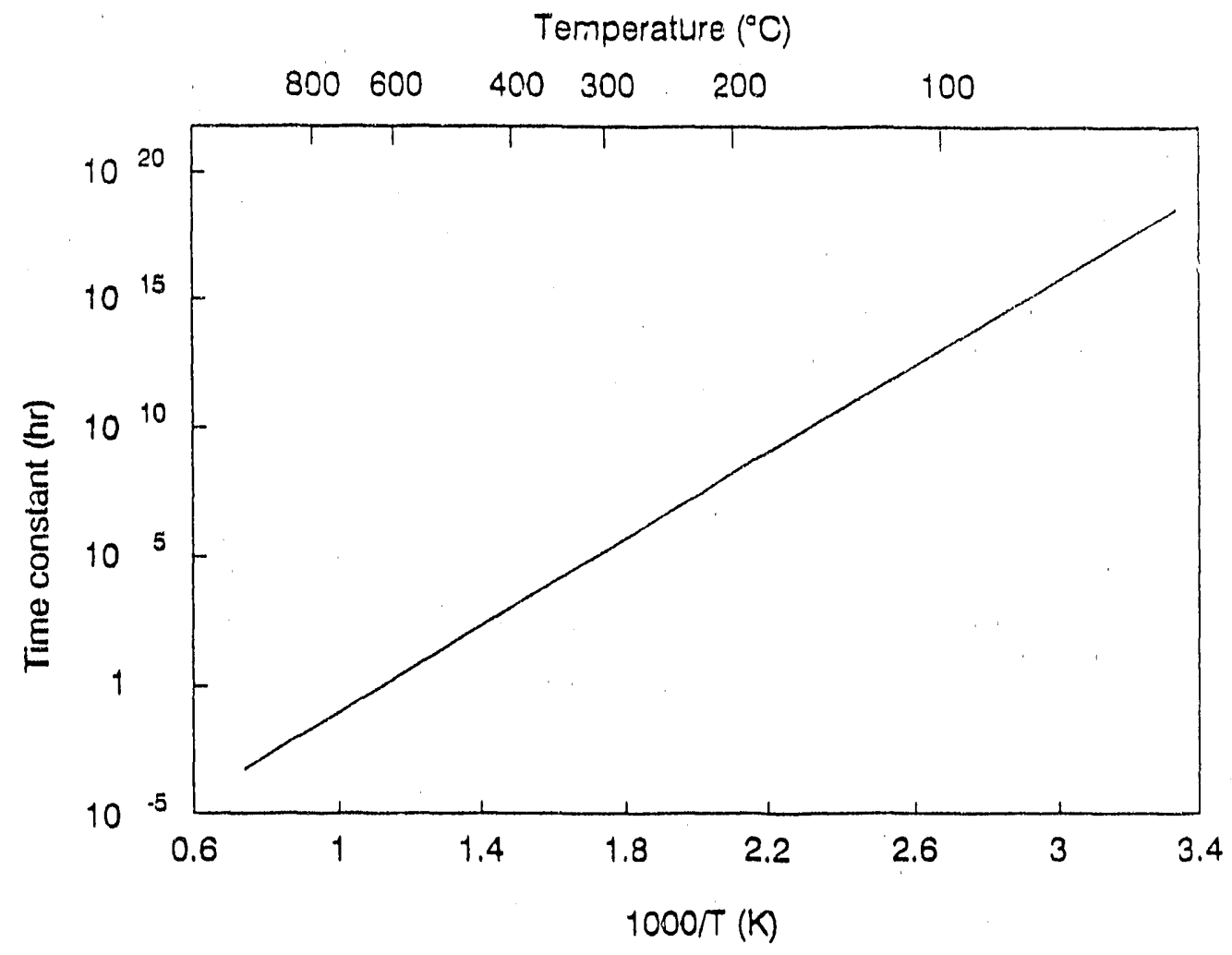

Figure 3. Transient times $\left(r^{2} / D_{s}\right)$ for self diffusion throug... a grain of radius $r=12 \mu \mathrm{m}$.

\section{TRITIUM MOVEMENT AND RELEASE}

\section{Conceptual Model}

Unlike He, which is considered essentially insoluble in Be, hydrogen has an apparent finite solubility following sieverts' law. The value of that solubility historically accepted is $3: 82 \times 10^{-8}$ atom/atom. $\mathrm{Pa}^{1 / 2}$, due to Jones and Gibson. ${ }^{19}$ The enthalpy of solution is given by them as very nearly zero. This value for solubility is in some doubt, however as will be discussed below.

Swansiger ${ }^{20}$ measured tritium solubility in high-purity Be and found that for temperatures above $700 \mathrm{~K}$, solubility was given by 


$$
S=0.084 \exp \left(-\frac{11510}{T}\right)\left(P_{a}^{-1 / 2}\right) .
$$

The solution enthalpy of about $97 \mathrm{~kJ} /$ Mole $(1 \mathrm{eV})$ is endothermic but substantially less than that required to form the hydride $(318 \mathrm{~kJ} / \mathrm{mole})$. At lower temperatures the apparent solubility exhibited somewhat erratic exothermic behavior. Swansiger assumed the erratic, low-temperature behavior was due to trapping, similar to what was seen by Wampler. ${ }^{21}$ Wampler had implanted deuterium into Be foils and found that the deuterium saturated in the $\mathrm{Be}$ at about $0.31 \mathrm{D} / \mathrm{Be}$. This seems associated with a maximum damage level tolerated in the $B e$ and is not inconsistent with the ideas presented here.

Hydrogen has a much higher diffusivity in Be than the self diffusion of Be atoms. It is given by Jones and Gibson as

$$
0=3.0 \times 10^{-7} \exp \left(\frac{-0.192 \mathrm{eV}}{k T}\right) \frac{\mathrm{cm}^{2}}{\mathrm{~s}} \text {. }
$$

If this is true, then at $300^{\circ} \mathrm{C}$ hydrogen diffusion is more than 81,000 times faster than self diffusion, but it is much less sensitive to temperature. Abramov et al. ${ }^{22}$ measured higher diffusivity values on extra grade $\left(D=6.7 \times 10^{-9} \exp [-28.4(\mathrm{~kJ}) / \mathrm{RT}]\right)$ and high grade $\left(D=8.0 \times 10^{-9} \exp [-35.1(\mathrm{~kJ})\right.$ /RT]) beryllium. Higher values yet have been reported by Pemsler and Rapperport. ${ }^{23}$ In any case, as tritium is formed in the Be lattice at modest temperatures, it should diffuse to sites of lower energy. By comparison with self-diffusion (and by inference to swelling) it moves rather quickly. It collects at lower energy sites which in this case are thought to be the bubbles or clusters of $\mathrm{He}$ and inclusions or grain houndaries where tritium atoms may react to form molecules. Be(OT) 2 may form at oxide inclusions that are present in all forms of Be considered for use in nuclear reactors. The STP formation enthalpy, $\Delta_{f} H^{\circ}$, for the reaction

$$
2 \mathrm{BeO}(\mathrm{cr}, \beta)+2 \mathrm{H}(\mathrm{g})-\mathrm{Be}(\mathrm{OH})_{2}(\mathrm{cr}, \beta)+\mathrm{Be}(\mathrm{cr})
$$

is $-67.9 \mathrm{~kJ} / \mathrm{mole}_{-} \mathrm{H}^{24}$ 
If tritium collects in bubbles, it probably exists as molecules. The partial pressure in the bubbles ray be expected to build by diffusion until a chemical equilibrium is established with tritium in the lattice. The magnitude of that pressure may be estimated. Suppose, for example, that 2000 appm tritium was prodiced in Be that had experienced $3 \%$ sweling (taken to be the valume of the bubbles), that the temperature was $25^{\circ} \mathrm{C}$, and that the ideal gas law was applicabie in the bubbles. These were the approximate conditions for samples used in dissoiution experiments performed by causey on highiy irradiated Be $\left(5 \times 10^{22} \mathrm{n} / \mathrm{cm}^{2}(F>1 \mathrm{MeV})\right)$. ${ }^{11}$ Mass conservation requires that. the sum of tha trition in the lattice, estimated from the pressure and solubility, combined with that in the bubbles, obtained from pressure, temperatu: 2, and volume, must sum to the total tritium produced less losses, decay, and chenically reacted tritium. In the present example, if the Jones and Gibson solubility is correct and no other storage or loss mechanisms were operative, we would expect the partial pressure of tritium in the bubbles to reach about $35 \mathrm{MPa}$ and constitute about $89.3 \%$ of the tritium. If Swansiger's solubility is right, the pressure would be $38 \mathrm{MPa}$ and the ratio of tritium in bubbles to that in solution, neglecting other reservoirs would be $2.5 \times 10^{11}$.

The Be tested by Causey was estimated tn have 24,000-30,000 appm He (based on measurements of He in other samples rom the same lot) and found to contain about 2,100 appm tritium after 8.2 years of deciy. Approximately $97.6 \%$ of the tritium was found to come out of the dissolving acid in the elemental molecular form. It suggests that much of the tritium in highly irradiated beryllium is stored as molecules in He bubbles or voids. But a sizeable fraction, perhaps $2.4 \%$, is also stored in another form, possibly as ditritoxide. That is less than what would be predicted based on the apparent solubility of Jones and Gibson (what they really saw was probably chemical storage) and consistent with the notion that the formation of He bubbles constitutes another reservoir for tritium. Tritium stored as ditritoxide would go into solution in the acid.

Also, in the thermal release experiments performed by Baldwin 16 and discussed in the following section, more than $95 \%$ of the tritium evolved came in a burst as the temperature exceeded $600^{\circ} \mathrm{C}$. This, too, appears connected to release from bubbles. 
These results suggest that the concept that some of the tritium moves to and is retained in bubbles is fundamentally correct. There may be other storage processes active as well such as chemical reactions. Probably very little tritium is stored in the lattice itself.

\section{Release Experiments}

Baldwin and co-workers ${ }^{16}$ conducted very careful experiments on heavily irradiated Be from the same lot as the sample examined by Causey to gain insight into storage and release characteristics pertinent to the ITER breeding blanket. Their experiments were very similar to those performed by Jones and Gibson. One difference, a significant one, was the use of once through sweep gas as opposed to the recycling of gas past the sample done by Jones and Gibson. In this section the data from these experiments will be analyzed to further establish the conceptual model to be presented.

Prominent questions in the present pursuit for ITER beryllium are whether tritium release from neutron-irradiated Be will be diffusion controlled, surface limited or regulated by some other process and whether the diffusivity reported by Jones and Gibson is correct. Reasons for believing that release is at least partially diffusion limited will now be discussed.

Idealizations - It has been shown ${ }^{25}$ that under the idealized assumption of one dimensional diffusion from a thin slab of thickness $2 L$, the released fraction, $f$, is given as a function of time by

$$
f=1-\frac{8}{\pi^{2}} \sum_{m=0}^{\infty} \frac{1}{(2 m+1)^{2}} \exp \left[\left(\frac{2 m+1}{2} \frac{\pi}{L}\right)^{2} D t\right]
$$

where $D$ is the diffusivity of tritium in the material. The value of $D$ may be extracted from experimental data in which the assumed conditions apply by noting that for large values of the dimensionless time, $\theta=t / \tau$, where the time constant, $\tau$, is given by

$$
\tau=\frac{L^{2}}{D}
$$

the series of Eq.(11) effectively reduces to a single term. In that case 


$$
D=-\frac{4 L^{2}}{\pi^{2}} \frac{d}{d t}[\ln (1-f)] .
$$

Recombination - If the release of tritium is limited by surface processes, however, the profiles will be visibly different. For second order recombination limited evolution, where the emission flux is proportional to a recombination coefficient, $K_{r}$, and the square of the dissolved gas atom concentration, it has been shown ${ }^{26}$ that for released fraction, $f$,

$$
1-f=\frac{L}{2 K_{r} c_{0} t+L}
$$

where $c_{0}$ is the dissolved gas atom concentration at time $t=0$. This may be written in terms of a dimensionless emission parameter, $\omega$, where

$$
\omega=\frac{2 K_{r} L c_{0}}{D}
$$

as

$$
1-f=\frac{1}{\omega \theta+1} .
$$

The $\theta$ in this equation is the same $t / \tau$ used previously. The emission parameter, $\omega$, characterizes emission from the metal. If diffusion is much more rapid than recombination, $\omega$ will be small, and emission will be surfacelimited. Conversely, if the diffusivity is comparatively small, $\omega$ will be large and diffusion will control emission. By assumption, $\omega$ must be small for Eq. (14) to apply.

When an overpressure of a reactive gas such as hydrogen is present, as it was in the experiments of both Jones and Gibson and of Baldwin, then we expect that emission of the tritium from the surface will be first order or proportional to the surface concentration to the first power. In such a case it is trivial to show that 


$$
\frac{d}{d t}[\ln (1-f)]--\frac{K_{r}}{2 L}
$$

where again the plate is assumed to be of thickness $2 \mathrm{~L}$. It is worth noting that this assumption gives a linear semi-log plot at all times, in contrast to the diffusion-limited case in which there is an initial transient that is nonlinear. Further, for this condition to apply the surface reaction must be significantly slower than diffusive processes. This will be met if $k_{r} \ll$ $2 D / L$.

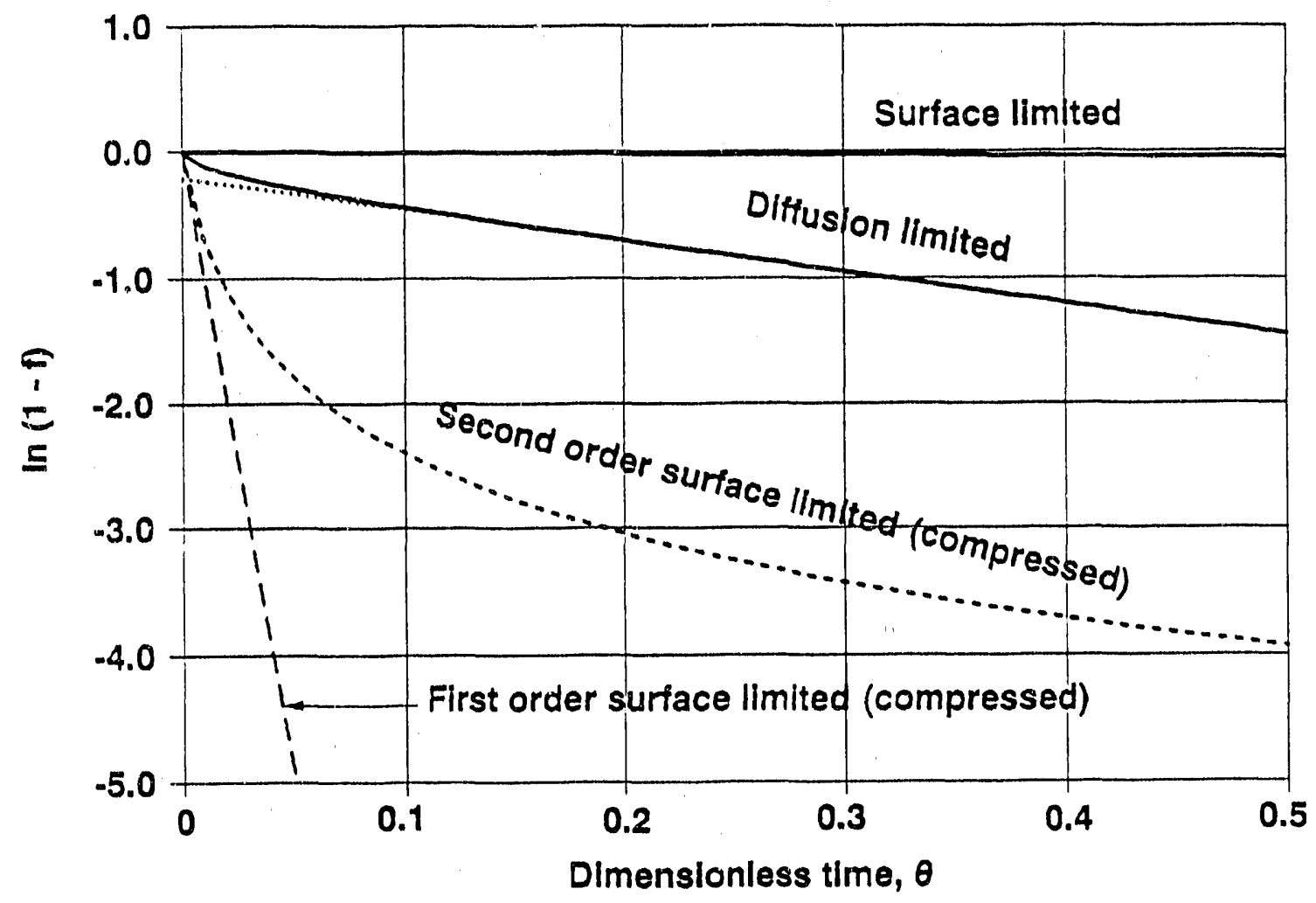

Figure 4. Idealized gas evolution curves for release fraction, $f$.

In Figure $4, \ln (1-f)$ is plotted as a function of $\theta$ for diffusion-limited emission (Eq.(11)) and both recombination-limited fluws (Eq. (16) with $\omega=0.1$ and $\mathrm{Eq} .(17)$ with $\mathrm{Kr}=0.2 \mathrm{D} / \mathrm{L})$. The diffusion-limited function is linear for $\theta>0.13$ whereas both surface-limited curves based on $\theta$ defined for the same diffusivity appear to be almost flat. In reality, for much longer times the 
second-order recombination limited curve has the shape shown by the broken line labelled as compressed in Figure 4 , which is the same curve plotted on a time scale 1000 times coarser. Also shown is the first order curve on the same compressed time scale. It may be worth noting that the shapes of the surface limited curves are unaffected by the shape of the specimen from which the tritium is evolved.

Diffusivity information only appears in experimerial data if emission is diffusion-limited, so we focus on the diffusion-limited curve. Two aspects of its shape are significant in attempting to derive diffusivity from experimental data. The most obvious is the linear slope that can be used to estimate diffusivitiy in the absence of trapping and surface effects. That slope, indicated by the superimposed dashed line in Figure 4 , is $-\pi^{2} / 4$. The other significant feature is the duration of the non-linear transient at the onset of the process. Assuming it lasts until $\theta=0.13$ ( $1 \%$ departure from exponential), we could also obtain $D$ from

$$
0-0.13 \frac{L^{2}}{t}
$$

where $t$ is the actual time required for the cumulative tritium release to become linear in semilog coordinates. Note that in establishing whetrer emission approaches idealized diffusion-limited flow from a slab, the $\theta=0.13$ point needs to come when $\ln (1-f)=-0,52$. This is also significant in verifying that the saturation value used to calculate 1 - $f$ is the right one.

On the other hand, if the emission is truly surface limited, no data on diffusivity will be available in the emission curves. Manipulation of Eq. (16) reveals that

$$
K_{r}=\frac{1}{2 c_{0} t}\left(\frac{f}{1-f}\right)
$$

which means that the quantity $t(1-f) / f$ sholild be a constant if recombination is second order $k_{r}$ is constant. If recombination is first order, then $\ln (1$ f) will be linear at all times. This provides a key to determining which processes may be operative in emission experiments. 


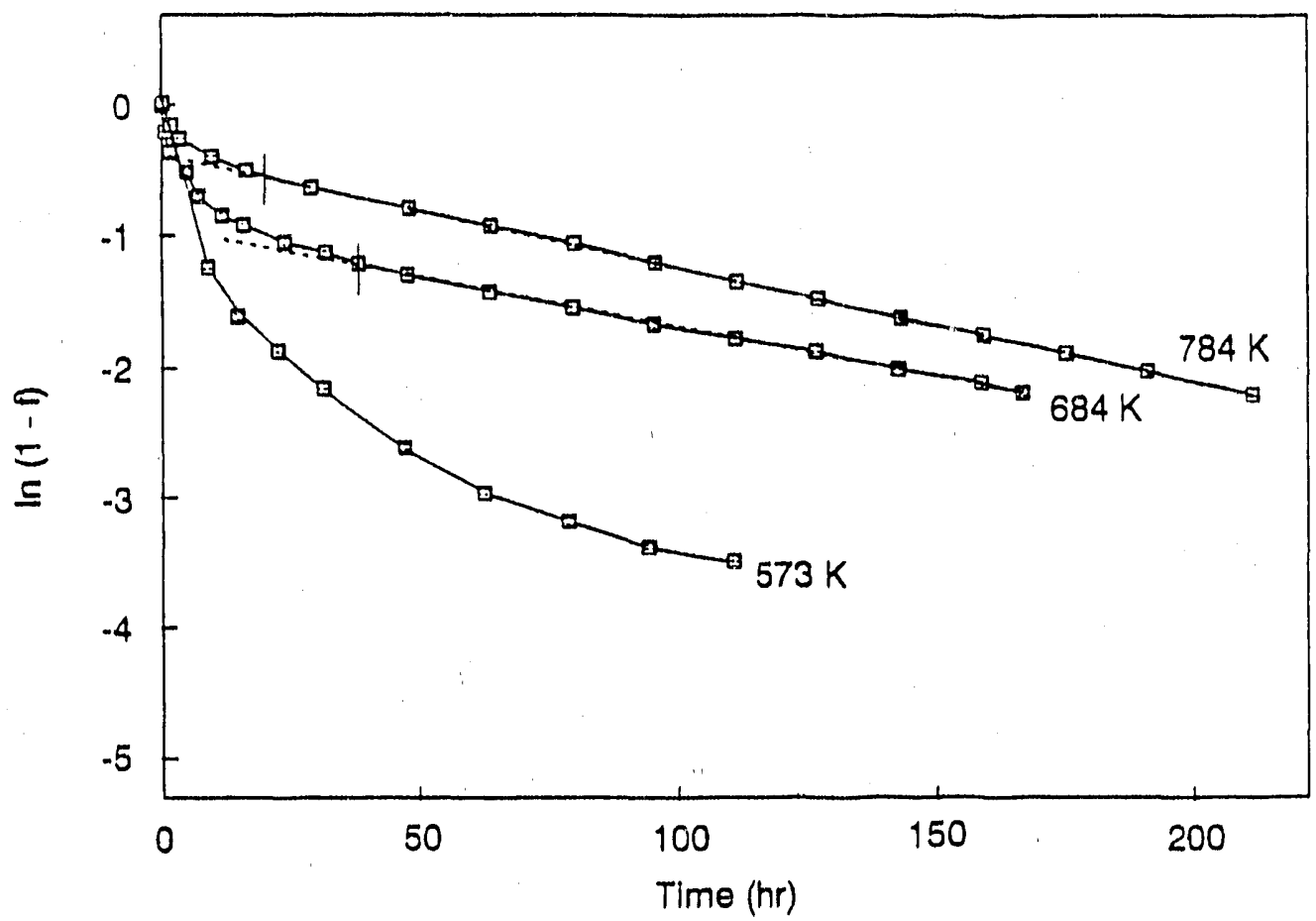

Figure 5. Semilog plot of data extracted from Baidwin's measuremerits. ${ }^{16}$

Figure 5 is an extraction from the data published by Baldwin ${ }^{16}$ for tritium release measurements on a Be disk $2.4 \mathrm{~mm}$ thick and $10 \mathrm{~mm}$ in diameter. Markers indicate values estimated graphically from his printed results. Notice that to the right of the points indicated with tick marks for the upper two temperatures there is good linearity of the data. The slopes of those two curves are in reasonable agreement. The $573-K$ data appear to have a different character, however.

The times associated with the tick marks in the two higher temperatiure curves are assumed to be those required for initial diffusive nc- inearities to decay, corresponding to $\theta=0.13$. However, for the 684-K curve, This poin: falls sufficiently below the required $\ln (1-f)=-0.52$ point that it may nci be assumed directly that the release is purely diffusion limited. Even so, the value of $D$ estimated using this point is $1.3 \times 10^{-8} \mathrm{~cm}_{2} / \mathrm{s}$, in excellent agreement with the value of $1.15 \times 10^{-8} \mathrm{~cm}^{2} / \mathrm{s}$ given by Eq. (9). The value for the 784-K curve of 25 hours may be used to evaluate the apparent diffusivity 
for tritium in the beryllium at that temperature as $2.08 \times 10^{-8} \mathrm{~cm}^{2} / \mathrm{s}$ with an uncertainty of about $50 \%$. Eq. (9) gives $1.75 \times 10^{-8} \mathrm{~cm}^{2} / \mathrm{s}$ at $784 \mathrm{~K}$. If the slope of the linear part of the $784-K$ curve is used for diffusivity, the value of $1.45 \times 10^{-8} \mathrm{~cm}^{2} / \mathrm{s}( \pm 10 \%)$ is derived. This is probably more accurate than using the transient decay time. Using the slope of the $684-K$ curve gives an even closer agreement with Eq.(9). Diffusivity estimates are summarized in Table 2 and compared with calculated values using Eq. (9).

Table 2. Diffusivity estimates from the slope of the linear part of the emission decay curves and from transient times.

\begin{tabular}{|c|c|c|c|}
\hline $\begin{array}{c}\text { Temperature } \\
(\mathrm{K})\end{array}$ & $\begin{array}{c}\text { Estimate based } \\
\text { on slope } \\
\left(\mathrm{cm}^{2} / \mathrm{s}\right)\end{array}$ & $\begin{array}{c}\text { Estimate based on } \\
\text { transient time } \\
\left(\mathrm{cm}^{2} / \mathrm{s}\right)\end{array}$ & $\begin{array}{c}\text { Calculation based } \\
\text { on Eg. }(9) \\
\left(\mathrm{cm}^{2} / \mathrm{s}\right)\end{array}$ \\
\hline 784 & $1.45 \mathrm{E}-08$ & $2.08 \mathrm{E}-08$ & $1.75 \mathrm{E}-08$ \\
\hline 684 & $1.19 \mathrm{E}-08$ & $1.30 \mathrm{E}-08$ & $1.15 \mathrm{E}-08$ \\
\hline 573 & - & $5.77 \mathrm{E}-09$ & $6.14 \mathrm{E}-09$ \\
\hline
\end{tabular}

To examine whether the 573-K data fit a second order recombinationlimited release model, the quantity $t(1$ - $f) / f$ is plotted for those data in Figure 6 . The values are almost constant over the last $3 / 4$ of the curve as may be seen. This is suggestive that a second order process may be controlling the release over that interval, but it is not controlling during the first part, and there is a hint that it may be changing toward the end of the time interval shown. Another argument against simple recombination in the $573-K$ data is the depth on the $\ln (1-f)$ scale to which the 573-K data go. As observed in Figure 4, on a time scale based on the diffusion transient, recombination limited release, either first or second order, is quite static and takes a long time to come to equilibrium. If diffusivity is reduced, as it will be at lower temperatures, it will take a longer real time to give the same value of $\theta$. Since the two higher temperature curves generally fit the diffusion constants of Jones and Gibson, we would expect the time scale for the 573-K data to be only about three times more extended in real time than that for the $784-K$ data. That implies the curve should be approachinn linearity when the test was terminated. So it appears that neither diffusion nor simple second order recombination are the sole governing mechanisms in the $573-K$ data. 


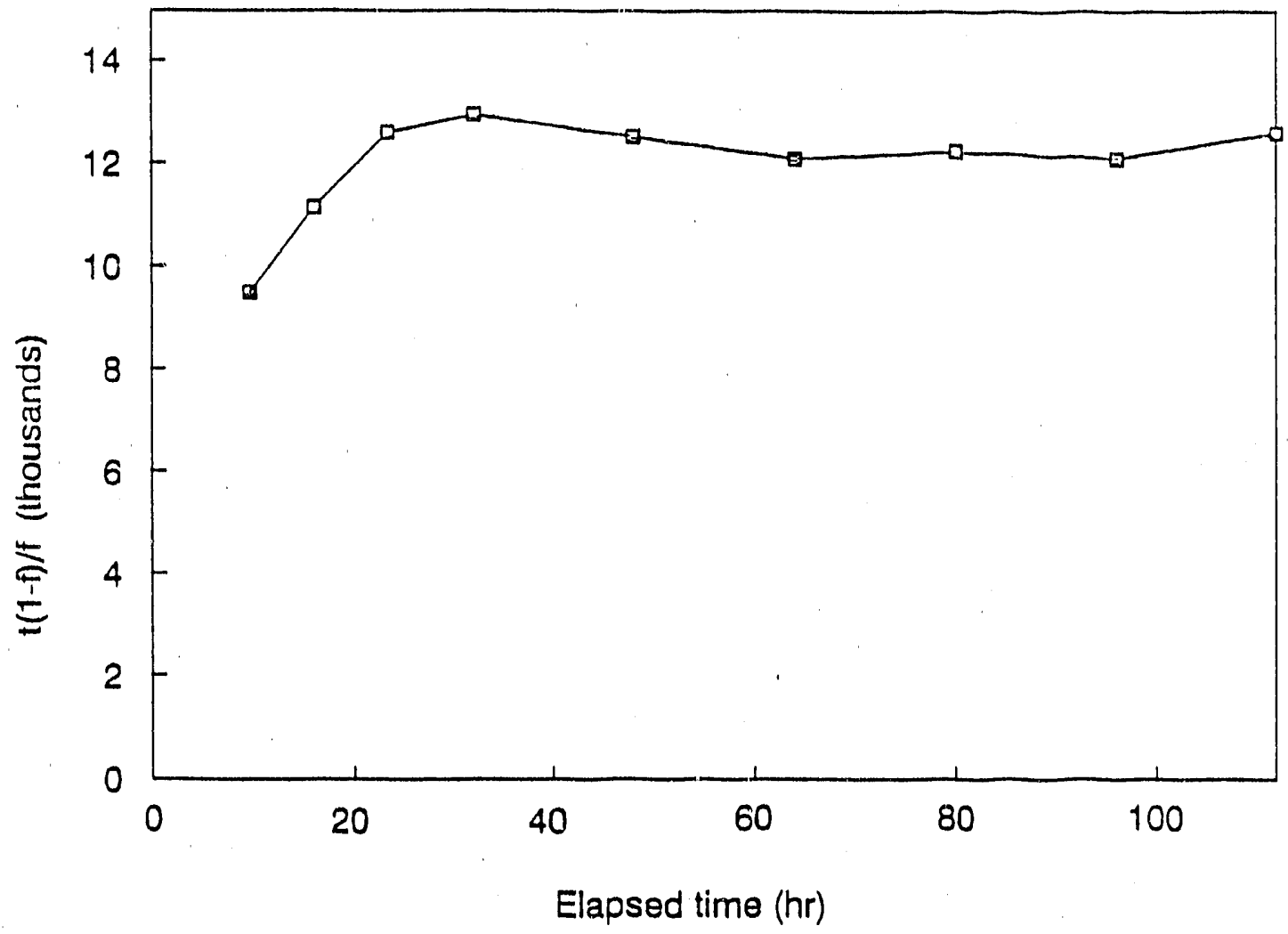

Figure 6. The constancy of the plotted values implies tritium release was partially limited by a second order process in the $573 \mathrm{~K}$ test.

Other - One possible explanation for the displacement in the $\ln (1-f)$ axis of both the $573-K$ and $684-K$ data is the release of tritium bound up in the surface oxides or in open porosity. This could come out on a very short time scale and appear to give added depth to the release transients. If this is the case and we assume that the $573-K$ data are just about to become linear when the temperature was changed, i.e., that the $\theta=0.13$ point occurs at $90 \mathrm{hr}$, the estimated value of the diffusivity is $5.77 \times 10^{-9} \mathrm{~cm}^{2} / \mathrm{s}$. This compares well with a value of $6.14 \times 10^{-9} \mathrm{~cm}^{2} / \mathrm{s}$ given by Eq. (9) as shown in Table 2.

Although the actual mechanism is as yet uncertain, it appears that quick release of tritium bound near surfaces combined with flow from the bulk is a reasonable explanation for the observed transient characteristics. 
Breakaway - Another interesting aspect of Baldwin's data may be observed if we examine the cumulative release fractions for each temperature. These are presented in an Arrhenius plot in Figure 7. The straight line part is a last squares fit, but the curved part to the left has a simple curve added to it to force a fit at the end point.

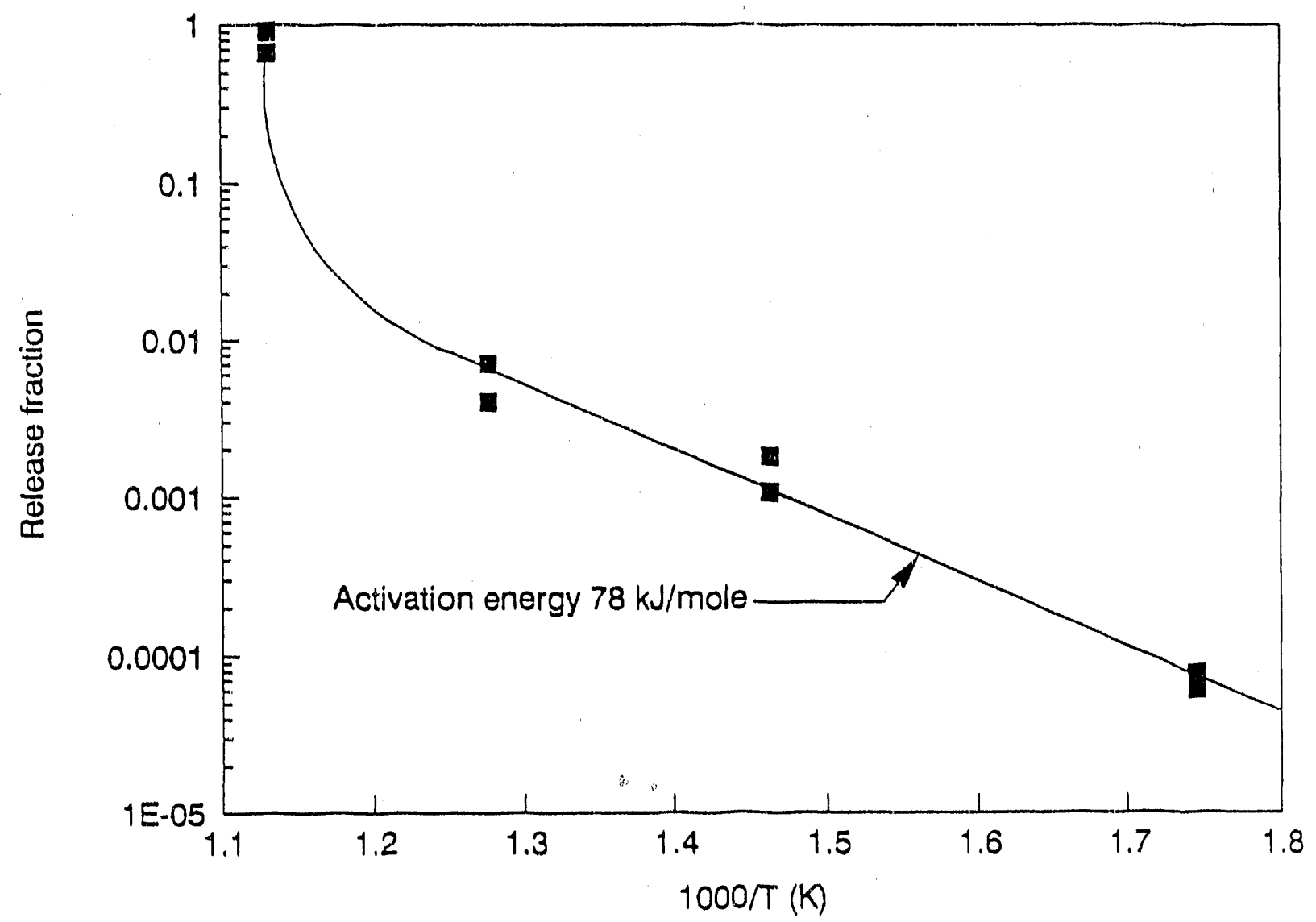

Figure 7. Arrhenius plot of the cumulative tritium release fraction in Baldwin's experiments. 16

The relatively linear character of the ciata to the right of $1000 / T \approx 1.2$ $\left(560^{\circ} \mathrm{C}\right)$ suggests that probably a single thermal activation process is responsible for the release of tritium at those temperatures. The slope of the linear part suggests an activation energy of $78 \mathrm{~kJ} / \mathrm{mole}$ of tritium atoms. For the highest temperature $(884 \mathrm{~K})$, however, the departure from linearity implies a differant process is dominant. This departure from linearity is totaily characteristic of "breakaway" swelling that is also known to take place at about the same temperatures. That leads to the conclusion that 
"breakaway" growth of bubbles is important in the release of tritium at temperatures above a critical temperature which for this sample is near $600^{\circ} \mathrm{C}$. If release was due to a single thermally activated process such as solubllity or diffusion, the curve would be linear at all temperatures.

One more observation on Baldwin's data relates to the complex character of the release rate at $884 \mathrm{~K}$. In the release rate curves published for the transient at $884 \mathrm{~K}$, there were two distinct peaks separated in time by eleven hours. In the first peak there was an immediate rate surge followed by an exponential decay. It gives an initial shape to the integrated emission curve similar to those seen on lower temperature tests, but it is too fast to be associated with the diffusion-limited release from the bulk of the sample. This seems to be due to the release of tritium bound up in surfaces. The larger, secondary release had a complex time history. There was a surge (larger but slower than in the first peak) followed by a rapid, linear initial drop and a second, slower, rather linear decay. The time constant for the second part was in reasonably good agreement with bulk diffusion transients predicted by Eq. (12) using Jones and Gibson diffusion data and the full specimen thickness. It may be that the steeper first linear segment is associated with a different diffusion length such as movement along grain boundaries rather than through the grains.

Tritium Storage - There are several aspects of these result: that may shed light on mechanisms for tritium storage in Be. The release fraction observation is one in particular. In the data both of Jones and Gibson and of Baldwin, heating the sample to successively higher temperatures resulted in the attainment of a new, lower equilibrium level of tritium in the sample. At less than the "breakaway" temperature this obeys an Arrhenius law and seems to be associated with a chemical process. When "breakaway" occurs, obviously a different process becomes active. Interestingly, in the Jones and Gibson data the emission at $800^{\circ} \mathrm{C}$, the next temperature tested after $600^{\circ} \mathrm{C}$, resulted in a substantially larger emission in their experiments than at the previous temperatures tested, though it was not so pronounced as in Baldwin's experiments. 
In the Jones and Gibson experiments, the tritium that came from the sample and got into the gas stream of their closed system stayed there. The rising tritium concentration in the gas created a chemical potential that was logically inferred to balance that of tritium assumed dissolved in the Be sample. Since there was an external tritium partial pressure, then as the temperature changes took place, one would expect the tritium in the lattice and/or traps to move into or out from the material to maintain chemical equilibrium with the gas pressure outside the metal. That apparent observation by Jones and Gibson gave rise to the value of solubility for tritium in Be published by them. The observation of a solution enthalpy of zero was a curious thing. They noticed that and proposed that the tritium may have been stored in traps.

In Baldwin's work, there was no buildup of tritium in the gas stream, but the same kind of saturation behavior was observed. If the tritium was held in the lattice or in simple traps, then conventional theory for the filling and emptying of traps ${ }^{26}$ implies that when exposed to an atmosphere in which there was no tritium, all the tritium, mobile and trapped, would come out eventualiy at any temperature. The rate limiting constraints would be the number and energy of the traps and the diffusivity. Provided the diffusivity was sufficiently high for the process to take place on an observable time scale, the traps would be seen to empty alony with the evolution of mobile tritium.

In Baldwin's experiments, the atmosphere surrounding the samples was once-through, research grade $\mathrm{He}$ spiked with $0.1 \% \mathrm{H}_{2}$. While $\mathrm{H}_{2}$ would have assisted in removing the tritium from the surface of the samples, isotopic exchange would have taken place in the metal, and the tritium transient should not have been stopped short of complete emptying by the presence of the $\mathrm{H}_{2}$.

If the tritium was in the voids or He bubbles as a simple diatomic gas, the enthalpy required for dissociation, assuming no solution enthalpy in the Be as reported by Jones and Gibson, would be approximately the hydrogen dissoctation enthalpy of $218 \mathrm{~kJ} / \mathrm{mole} \mathrm{H}(2.26 \mathrm{eV} / \mathrm{H})$. In comparison with the -evident diffusion activation energy of $0.192 \mathrm{eV}$, it seems reasonable to believe that tritium diffusing to a vold or He bubble and combining into a 
molecule would stay there for a long time. When these structures move or grow rapidiy and become interconnected, as they can at elevated temperatures, the tritium would be carried with them. This seems to be the explanation for the "breakaway" release of tritium seen both by Baldwin and to a lesser extent by Jones and Gibson. The lesser burst seen by Jones and Gibson is probably a reflection of the lower number of such structures in the arc cast sample they used as compared with the powder metallurgy process formed material with a large number of He bubbles used in Baldwin's experiments.

In addressing the cheinical storage process, tritlum may be stored as tritoxide that decomposes with increasing temperature. All Be has some BeO inclusions that can react to form $B e(O T)_{2}$. These inclusions also tend to collect at grain boundaries. The ditritoxide, while not spontaneously formed from BeO with molecular tritium gas, is energetically stable with respect to single tritium atoms such as would be found in the Be lattice. The formation enthalpy for $\mathrm{Be}(\mathrm{OH})_{2}$ from $\mathrm{BeO}$ and $\mathrm{H}$ is $-67.8 \mathrm{~kJ} / \mathrm{mole}^{\mathrm{H}}$ at STP while from $\mathrm{BeO}$ and $\mathrm{H}_{2}$ it is $+300.6 \mathrm{~kJ} /$ mole $\mathrm{H}_{2}$. The process may have to go through an intermediate stage of BeOT formation that is not favorable $\left(\mathrm{A}_{\mathrm{f}} \mathrm{H}^{\circ}(\mathrm{BeOH})=+269\right.$ $\mathrm{kJ} / \mathrm{mole}$ ), but the overall reaction could be augmented or catalyzed by the $B e$ metal lattice. Interestingly, the activation erergy in Baldwin's data (Figure 7) is very close that associated with dissociation of the ditritoxide (assumed similar to that of ditritoxide), so the monotritoxide stage is expected not to be rate limiting.

Apparently, then, tritium that makes it into the lattice either by nuclear transmutation or by suriace dissociation at high temperature or pressure will diffuse to BeO inclusions where the ditritoxide will be formed. Under the action of subsequent heating the ditritoxide will dissociate. Supposing that the solubility of tritium in the lattice is very low, much lower than reported by Jones and Gibson, the tritium released from the ditritoxide, in excess of what the lattice will hold, will diffuse to the surface where it will recombine or be removed by the surface hydrogen. The reverse process of absorbing tritium from a surrounding atmosphere is difficult energetically. One ought not to see tritium reabsorbed at lower temperatures in a Jones-and-Gibson-type experiment if this model is correct. 
This ditritoxide dissociation process would explain why in Baldwin's experiments at less than $600^{\circ} \mathrm{C}$ an abrupt surface release is observed followed by one dominated by diffusion. The quick release should be associated with surface oxides, while the diffusion-limited one is associated with embedded oxide inclusions.

\section{EVOLUTION MODEL}

Having reviewed possible processes pertinent to the release of tritium from irradiated Be, the following summary seems to be an appropriate definition for a retention and release model for ITER:

Tritium production will be generally proportional to the fluence of neutrons with energies $E>1 \mathrm{MeV}$. The exact scale factor has not yet been determined, but a reasonable value may be obtained using data from fission reactor experiments and activation calculations. He production of 0.0066 $\mathrm{He} / \mathrm{Be} / 10^{22} \mathrm{n} / \mathrm{cm}^{2}$ is estimated, and a $\mathrm{He} / \mathrm{T}$ ratio of about 17 should be observed. For a neutron fluence of $4.2 \times 10^{21} \mathrm{n} / \mathrm{cm}^{2}\left(3 \mathrm{MWy} / \mathrm{m}^{2}\right)$ trititum production in the Be is roughly estimated to be $163 \mathrm{appm}$. This gives a total production for a 200 tonne breeding blanket of $10.9 \mathrm{~kg}$ which is higher than values others have used. ${ }^{27}$

The solubility for tritium in Be as given by Jones and Gibson appears to be incorrect. Rather, especially at. low temperatures, the capacity of the Be for tritium appears to be mainly connected with a combination of chemical storage, probably as ditritoxide, in inclusions and at grain boundaries combined with physical storage as gas molecules in voids and He bubbles. Thermally activated release from the chemical storage at temperatures less than the "breakaway" temperature fits readily with the Arrhenius relation seen in Figure 7.

The breakaway temperature varies with helium production (fast neutron fluence) and other factors such as impurities and fabrication processes. For irradiation at temperature such as will be seen in ITER service, Eq.(5) with 
$\Delta V / V$ of about $10 \%$ for the breakaway value is adopted for determining "breakaway" temperature. Complete gas release is expected when $\Delta V / V \approx 10 \%$

We may be justified in assuming that below the "breakaway" temperature, much of the tritium will be stored in bubbles and voids. If the Be is fully dense, the volume available for such storage is that due to swelling given by Eq. (5). At low densities ( $65-80 \%$ dense) this reservoir may need to be at least partially discounted, particularly at high fluences. This follows from the assumption that in highly irradiated, dense material most of that reservoir volume is at grain boundaries. In low density material many if not most of the grain boundaries are connected by porosity to the surface. For low density material at low fluence and modest temperatures, there will not be appreciable bubble motion to the grain surface, so the reservoir will still be active. Most of the Be in the ITER blanket will fall in this regime under normal operating conditions.

Tritium inventory in the lattice should be negligibly small and correspond with solubility given by Eq. (8) The driving potential for the lattice inventory should be that associated with the partial pressure of tritium molecules in gas bubbles and voids. The fraction of the tritium found in oxide inclusions cannot be determined from the information available here. Experimentally it has been found to be on the order of $2-4 \%$ of the total.

Release kinetics will be density dependent and partially diffusion controlled. It appears that the diffusivity given by Jones and Gibson is adequate to describe tritium release from the bulk at less than critical temperature for standard nuclear grade Be. For fully dense material, the time constant for diffusive emission will be that based on the thickness of the plate 0 , block. For partially dense materiai, the diffusion time may be much less. If the material is highly porous, the scaling length may be only one or two grain diameters. The tritium that is not diffusion controlled will emerge effectively in a short burst. The fraction of the tritium produced that will reside in surfaces cannot be adequately determined at the present time. However, examining the data in Figure 5 , a reasonable model may be that tritium bred in the lattice will undergo random diffusion. That which 
encounters an oxide inclusion or oxidized surface will be chemically trapped. That which encounters a void or bubble will be trapped there.

Release of tritium from the oxides is activated by thermal processes. When a temperature transient above the critica' temperature occurs, an additional release mechanism becomes active. Eubble "breakaway" occurs with the attendant release of most of the retained tritium. The release fraction would be expected to approach $100 \%$ if the temperature transient was to be high enough and last long enough. An interesting question is how loing this transient must last before the large burst is seen. In Baldwin's work at $611^{\circ} \mathrm{C}$ (884 $\mathrm{K}$ ) the time was ten hours. In the experiments shown in Figure 2 conducted at $700^{\circ} \mathrm{C}$, the swelling time, which is believed to correspond to gas release times, varied widely but was only one hour in one instance. This phenomena will vary so widely with material composition, structure, noitron fluence, temperature, and probably other factors as wel1, but Barnes' models discussed above will be used for estimates here. Eq. (5) will be assumed to apply to swelling that takes place while ITER is in operation, and Eq.(6) will be used to estimate additional swelling during thermal transients. When the swelling locally exceeds $10 \%$, release of bubble-trapped tritium will be assumed.

The total evolution history in a transient will be an integration in time over the volume of the blanket Be. The integrand will be the sum of two release rates. One will be due to ordinary classical diffusion required to vent the tritium generated by decomposition of the ditritoxide. That may be modelled as diffusion limited beginning with uniform oversaturation of the lattice. The diffusion length will depend on the form of the Be. The other term will only activate when the temperature exceeds the critical temperature. It will be assumed to come out immediately as it is released.

The detailed computation of this release history has not been performed yet, partly because full neutronics calculations have not been performed over the entire blanket. Temperature and He distributions have been calculated for the Be multiplier in each of four different zones at the mid-plane under normal operating conditions. ${ }^{28}$ Figure 8 shows the general configuration of the blanket at that location, ${ }^{29}$ and Table 3 lists the pertinent data for each 


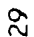
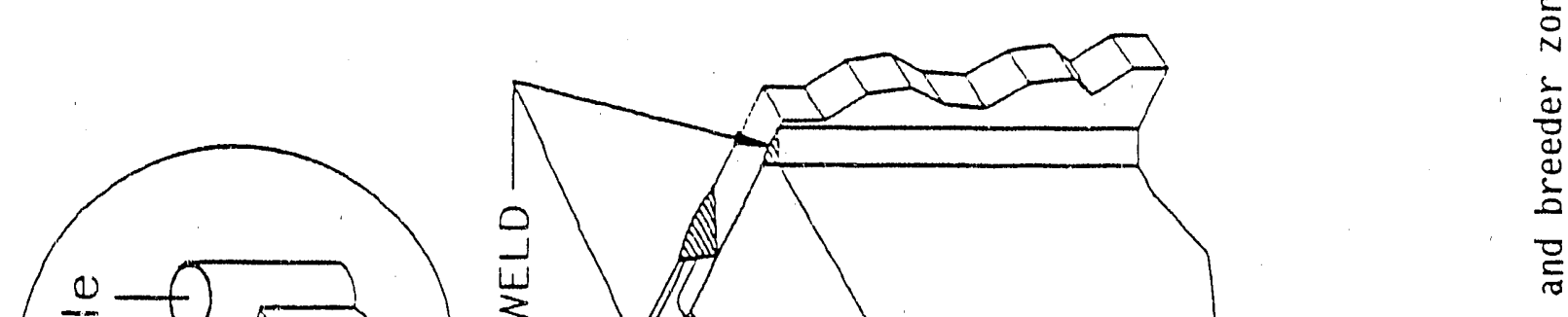

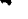
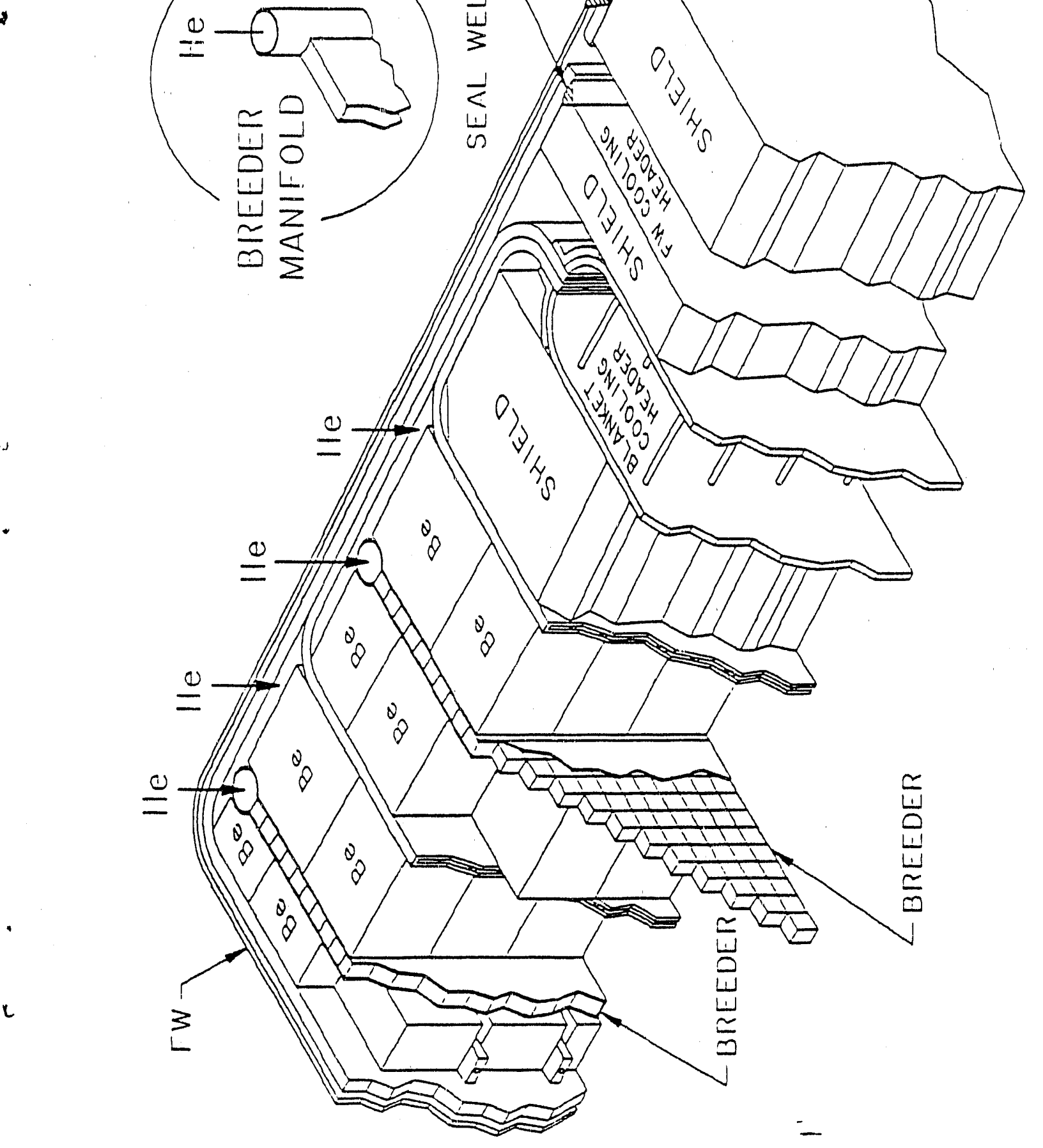
Table 3. Estimates made of operating temperatures and He production rates for various locations in the Be multiplier regions at the midplane of the ITER blanket. Swelling estimates are from Eq. (5) after three years.

\begin{tabular}{|c|c|c|c|c|}
\hline Be Zone & $x(\mathrm{~mm})$ & $I\left({ }^{\circ} \mathrm{C}\right)$ & $\begin{array}{l}\text { He rate } \\
(\mathrm{appm} / \mathrm{yr})\end{array}$ & $\begin{array}{l}\text { Three-year } \\
\text { Swelling }\end{array}$ \\
\hline 1 & $\begin{array}{r}0 \\
10 \\
20 \\
30 \\
34 \\
\end{array}$ & $\begin{array}{l}280 \\
316 \\
351 \\
387 \\
401 \\
\end{array}$ & $\begin{array}{l}3961 \\
3698 \\
3452 \\
3137 \\
3137 \\
\end{array}$ & $\begin{array}{l}1.5216 E-04 \\
2.5087 E-04 \\
3.8264 E-04 \\
5.4299 E-04 \\
6.4353 E-04 \\
\end{array}$ \\
\hline 2 & $\begin{array}{l}\frac{0}{10} \\
20 \\
30 \\
40 \\
50 \\
59\end{array}$ & $\begin{array}{l}\frac{401}{366} \\
330 \\
295 \\
259 \\
224 \\
192\end{array}$ & $\begin{array}{l}\frac{2680}{2435} \\
2212 \\
2010 \\
1826 \\
1659 \\
1508\end{array}$ & $\begin{array}{l}\frac{5.2856 E-04}{3.0264 E-04} \\
1.6280 E-04 \\
8.3901 E-05 \\
3.9669 E-05 \\
1.7574 E-05 \\
7.5806 E-06\end{array}$ \\
\hline 3 & $\begin{array}{r}0 \\
10 \\
20 \\
30 \\
40 \\
50 \\
57 \\
\end{array}$ & $\begin{array}{l}138 \\
188 \\
237 \\
287 \\
337 \\
386 \\
421 \\
\end{array}$ & $\begin{array}{r}1331 \\
1238 \\
1151 \\
1070 \\
995 \\
925 \\
960 \\
\end{array}$ & $\begin{array}{l}1.5060 E-06 \\
5.3767 E-06 \\
1.4555 E-05 \\
3.3394 E-05 \\
6.6385 E-05 \\
1.1653 E-04 \\
1.8463 E-04\end{array}$ \\
\hline 4 & $\begin{array}{l}10 \\
10 \\
20 \\
30 \\
40 \\
50 \\
60 \\
70 \\
71\end{array}$ & $\begin{array}{l}\frac{427}{384} \\
342 \\
299 \\
256 \\
213 \\
170 \\
127 \\
123\end{array}$ & $\begin{array}{l}\frac{708}{653} \\
602 \\
555 \\
511 \\
471 \\
435 \\
401 \\
369\end{array}$ & $\begin{array}{l}\frac{1}{7} .3493 E-04 \\
3.3553 E-05 \\
3.8038 E-05 \\
1.7926 E-05 \\
7.6340 E-06 \\
2.8712 E-06 \\
9.2120 E-07 \\
2.3839 E-07 \\
1.8876 E-07\end{array}$ \\
\hline
\end{tabular}

Distances, $x$, measured from the plasma side of each zone face.

node evaluated. Zone 1 is the multiplier region nearest the plasma, and 4 is furthest from it.

Eq. (5) was used to determine if any tritium trapped in bubbles may be released during routine operations over three years. Swelling was found not to exceed 0.001 in any of the nodes, so we conclude none of the bubble-trapped tritium is released. To get some feeling for the release fraction during a 
thermal transient, the transient was modelled as a saturating-exponential transition from the local operating temperature identified in Table 3 to a target temperature varying from $500^{\circ} \mathrm{C}$ to $900^{\circ} \mathrm{C}$ with a 10 -hour time constant. The elements closest to the breeding zones (underlined in Table 3 ) experience the greatest swelling in each zone, and their swelling histories, given by Eq. (6) were tracked over 90 hours during the above described thermal transients. Those histories are given in Figure 9. In reality, one would not expect swelling to exceed $30 \%$, shown as a practical maximum line in Figure 9 .
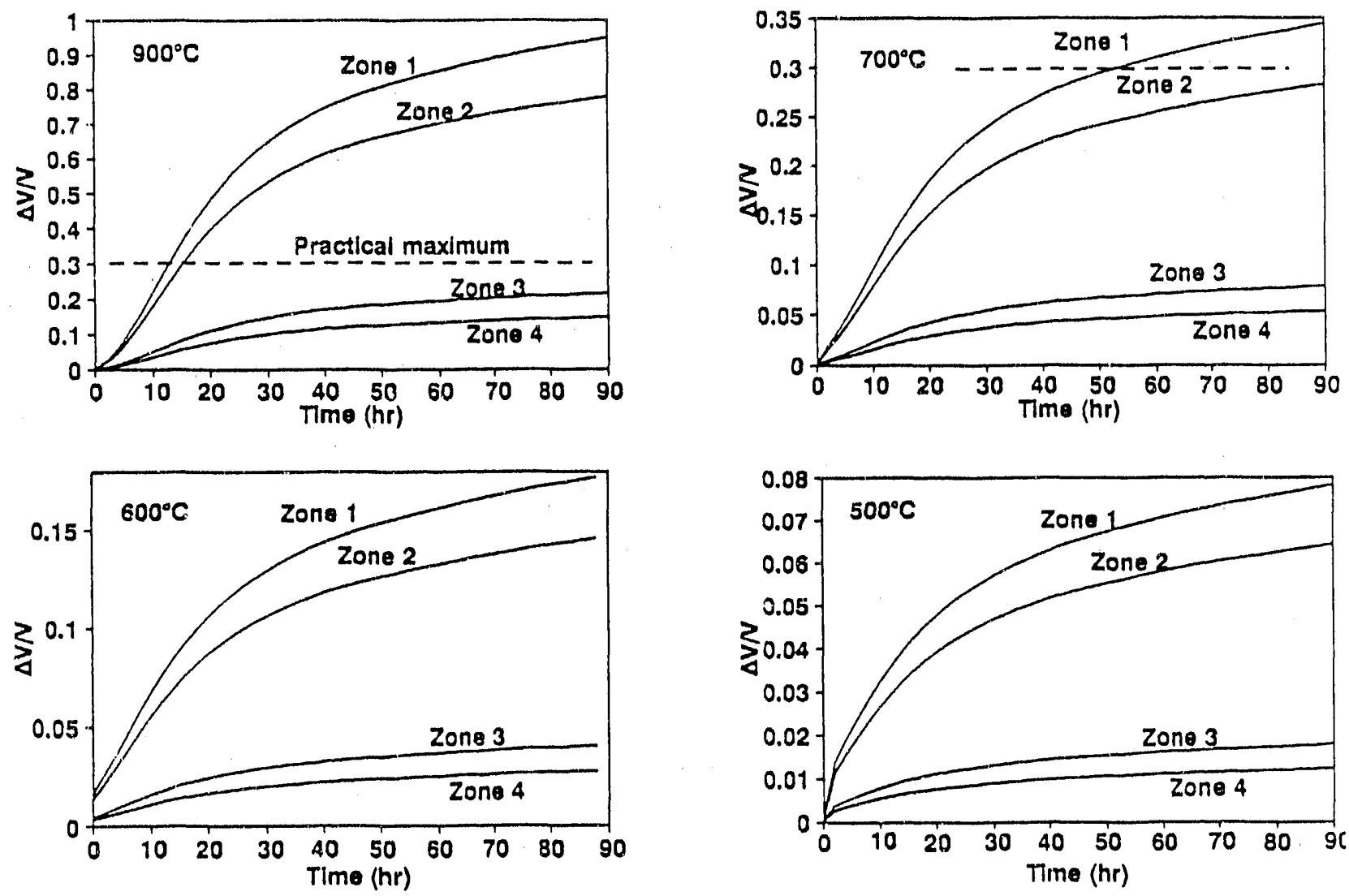

Figure 9. Comparison of swelling predictions in selected nodes for thermal transients to the temperatures indicated.

By making similar calculations for each of the nodes listed in Table 3 and monitoring the time in each therma? transient when each node reached $10 \%$ swelling, it was possible to make an estimate of the release fraction for bubble-trapped tritium as a function of time. The results of that calculation are given in Figure 10 . The accuracy of this result is 1 imited by the degree 
to which swelling conditions at the midplane are representative of those elsewhere in the blanket. This is believed to be a conservative calculation because neutron flux, and hence He production and swelling, is greatest at the midplane.

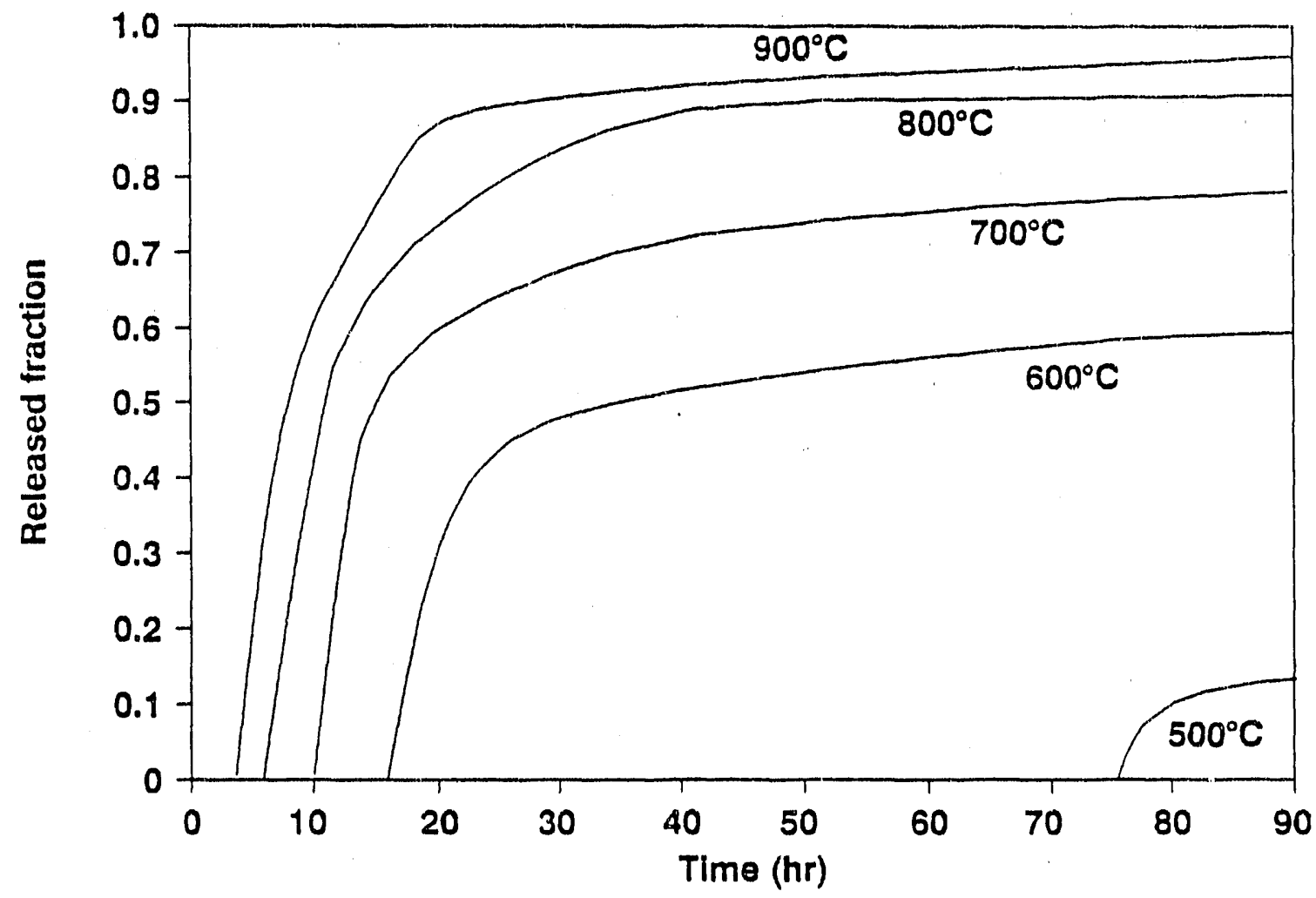

Figure 10. Release fraction histories for tritium trapped in He bubbles in the ITER blanket during thermal transients to the temperatures indicated.

\section{CONCLUSIONS}

Data collected over the years on the effects of neutron irradiation on Be have shown that $H e$ and tritium are produced in rather predictable quantities. Experiments to determine the way in which tritium is retained in irradiated $B e$ and released from it have been analyzed. The model that has emerged from this review assumes that (a) the tritium is mainly in the He bubbles formed, with a small quantity retained as $\mathrm{Be}(\mathrm{OT})_{2}$ in oxide inclusions; (b) if the temperature exceeds a critical temperature set by Eq. (5) or Eq. (6) 
depending on whether the temperature transient is slow or fast compared with the neutron fluerice, a process of rapid bubble growth and coalescence results in the release of essentially all the remaining tritilum. A computational model to be used in estimating tritium releases from Be in an ITCR blanket during routine operations and accident transients has beer developed. Initial estimates are that a majority of the tritium stored in the ITER blanket $\mathrm{Be}$ will be raleased during temperature transients exceeding $600^{\circ} \mathrm{C}$.

\section{REFERENCES}

1. M. C. Billone, C. E. Johnson, and A. R. Raffray, Presented at: ITER Blanket and Shield Workshop, Garching, FRG (January 31 - February 6 , 1990).

2. K. A. Walsh, in: Beryllium Science and Technology, Vol. 2, Eds. D. R. Floyd and J. N. Lowe (Plenum Press, New York, 1979) p.5.

3. E. H. Ottewitte, Idaho National Engineering Laboratory, private communication.

4. "U.S. Technical Report for the ITER Blanket/Shie'd, A. Clanket, "ITER-TNBL-5-0-3, July-November 1990, Garching, Federal Republic of Germany, $p$. 158 .

5. C. S. Ells and C. W. Perryman, J. Nucl. Mater. 1 (1959) 73.

6. J. M. Beeston, unpublished results, Idaho National Engineering Laboratory.

7. R. L. Tromp, in "Materials Testing Reactor - Engineerilig Test Reactor Technical Branches Quarterly Report, January 1 - March 31. 1962," IDO16781, AEC Research and Development Report, Reactor Technology, TID-4500 (17th Ed.), June 15, 1962.

8. J. M. Beeston, et a1., INEL Report EGG-FSP-912.5 (June 19SÜ).

9. J. M. Beeston, EG\&G Report, TREE-1063 (October 1976).

10. P. Lorenzetto, ITER Workshop on Blanket/Shield, Garching, FRG (January February 1990).

11. J. M. Beeston et a1. J. Nucl. Mater. 12? \& 123 (1984) 802.

12. R. S. Barnes, J. Nuc1. Mater. 11 (1964) 135.

13. R. S. Barnes arid R. S. Nelson, in: Metaijurgical Society Conferences (AIME, Asheville, NC, 1965) p.225. 
14. E. E. Gruber, in: Metallurgical Society Conferences (AIME, Asheville, NC, 1965) p.?.69.

15. J. B. Rich, G. B. Redding, and R. S. Barnes, J. Nucl. Mater. 1 (1959) 96.

16. D. A. Baldwin, 0. D. Slagle, and D. S. Gelles, "Tritium Release from Irradiated Beryllium at Elevated Temperatures," PNL-SA-16998, Pacific Nort.hwest Laboratory, November 1989.

17. P. Hoffmann and W. Dienst. J. Nucl. Mater. 171 (1980) 203.

18. N. L. Peterson, J. Nucl. Mater. 69-70 (1978) 3.

19. P. M. S. Jones and R. Gibson, J. Nucl. Mater. 21 (1967) 353.

20. W. A. Swanstger, J. Vac. Sci. Tech. A 4, 3 (May/June 1986) 1216.

21. W. R. Wampler, J. Nucl. Mater. $122 \& 123$ (1984) 1598.

22. E. Abramov et al., "Deuterium Permeation and Diffusion in High Purity Beryllium," CFFTP G-90i3 (May 1990), submitted to J. Nuc1. Mater.

23. J. P. Pemsier and E. J. Rapperport, Trans. Metal1. Soc. AIME, 230 (1964) 90.

24. M. W. Chase et a1., JANAF Thermochemical Tables, Third Edition, Journal of Physical and Chemical Reference Data, 14 (1985) Supplement No. 1.

25. J. Crank, The Mathematics of Diffusion (Clarendon Press, Oxford, 1979).

26. G. F. Longhurst, INEL Report EGG-FSP-8766 (October 1969).

27. D. L. Smith, presentation to ITER Steering Committee - US, Dallas, TX (June 19-20, 1990).

28. M. C. Billone, ANL, Memorandum to D. L Smith (December 1, 1989).

29. "U.S. Technical Report for the ITER Blanket/Shield, A. Blanket," ITER-TNBL-5-0-3, July-November 1990, Garching, Federal Republic of Germany, p. 5. 

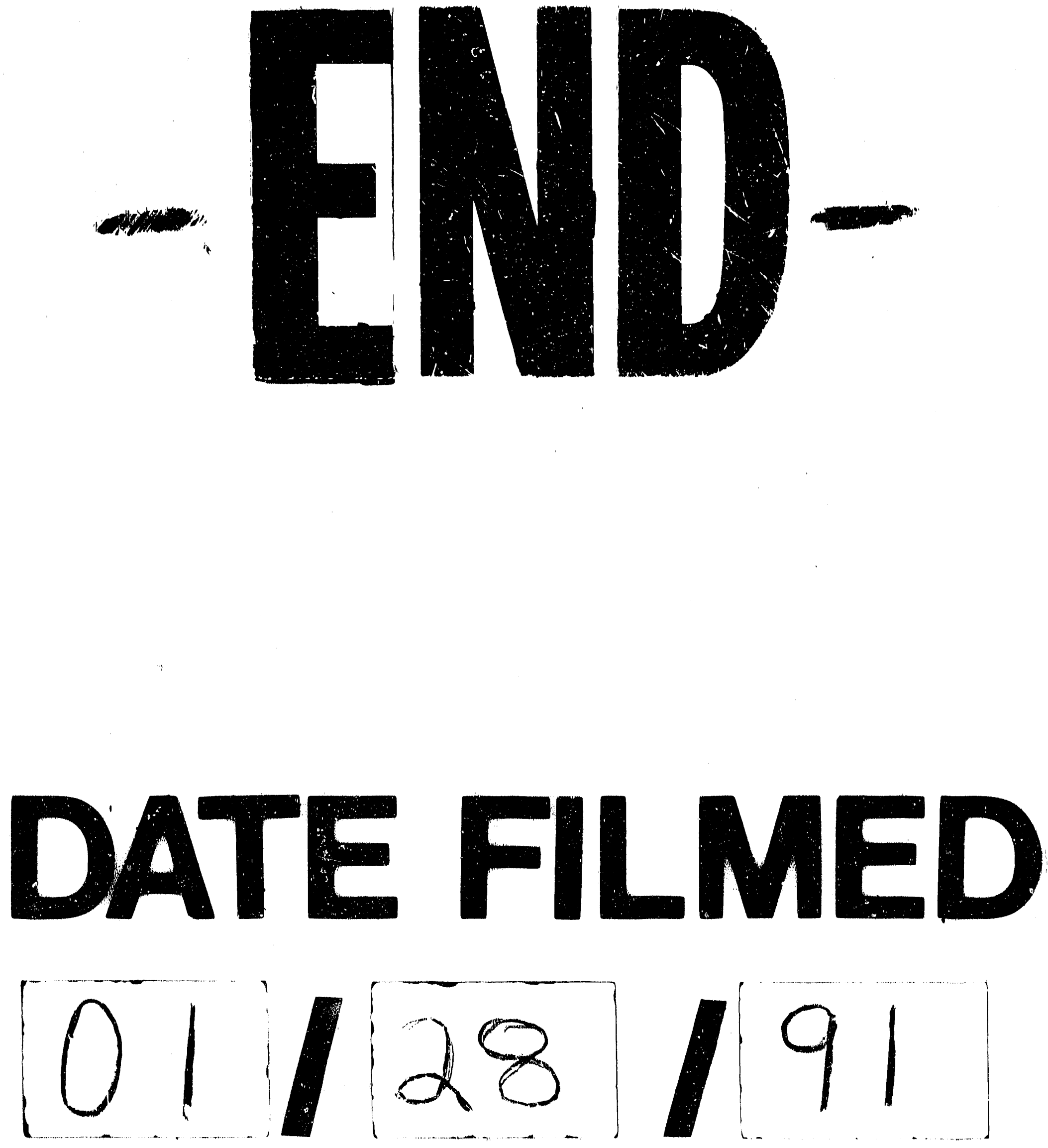
